\title{
Can We Expect Something from Prohepcidin Measurement in Hemodialysis Patients?
}

\author{
Theodoros Eleftheriadis ${ }^{a}$ Vassilis Liakopoulos ${ }^{a} \quad$ Charalambos Kartsios $^{b}$

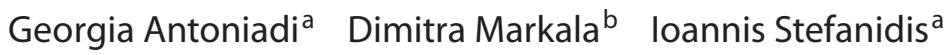 \\ a Department of Nephrology, University Hospital of Thessaly, Larissa, and ${ }^{\mathrm{b}}$ Laboratory of Hematology, \\ Theagenion Anticancer Hospital, Thessaloniki, Greece
}

Sir,

We read the article by Hsu et al. [1] that was recently published in your journal. The authors evaluated the effect of plasma prohepcidin on iron metabolism and erythropoiesis - in relation to inflammation as well - in hemodialysis (HD) patients. Their results were unexpected, since they detected a positive correlation between prohepcidin and hematocrit, no correlation with iron metabolism markers and CRP, and a negative correlation with IL-6. These results are very disappointing regarding the role of hepcidin in anemia of chronic disease and the resistance in recombinant erythropoietin therapy in HD patients.

Our team performed a similar study, which is going to be published in a future issue of Acta Haematologica [2]. It has already been presented in abstrcat from in the XLIII ERA-EDTA Congress. We also failed to detect a correlation of serum prohepcidin with various serum iron metabolism markers and CRP. However, multiple linear regression analysis considering age, inflammation, iron adequacy, erythropoietin dose and prohepcidin levels revealed that prohepcidin was the major determinant of hematocrit, but in a negative way. Malyszco et al. [3] also showed, in a univariate analysis, that prohepcidin correlated negatively with hematocrit. The negative correlation of prohepcidin with hematocrit seems reasonable, since the prohepcidin hyperproduction due to microinflammation usually encountered in
HD patients, or its accumulation due to renal failure, logically inhibits the iron release by macrophages, limiting its availability for erythropoiesis [4]. In accordance with the negative correlation between prohepcidin and hematocrit are the findings of Dallalio et al. [5], who in a recent in vitro study detected that hepcidin can contribute to anemia not only through an effect on iron metabolism, but also through inhibition of erythroid progenitor proliferation and survival.

What then is the explanation for the discrepancy among the three studies regarding the correlation of prohepcidin with hematocrit? Why was no relation detected between prohepcidin and markers of iron metabolism? The same kit was used for accessing prohepcidin levels in HD patients and its mean value was similar in all three studies (200-250 ng/ml). Is prohepcidin measurement useless for understanding better the anemia in HD and consequently as a marker of erythropoietin resistance in the future?

In our opinion, at the present time we are not able to answer the above question due to the complex interrelations among the various factors involved in the regulation of hepcidin expression. For example, serum iron and transferrin saturation are markers of iron metabolism but are also influenced by inflammation, which decreases their levels. Ferritin is a marker of iron stores and an acute phase reactant. Inflammation increases CRP as well as hep- cidin levels. Both iron deficiency and inflammation are quite common in HD patients. Finally, intravenous iron and erythropoietin administration, which is almost universal in HD patients, can significantly influence hepcidin expression. A study that will use the gold standard for evaluating iron availability for erythropoiesis, i.e. bone marrow iron stain, is needed in order to definitely clarify the role of hepcidin in the pathogenesis of anemia in HD patients and of the serum prohepcidin levels as a clinical marker.

\section{References}

1 Hsu SP, Chiang CK, Chien CT, Hung KY: Plasma prohepcidin positively correlates with hematocrit in chronic hemodialysis patients. Blood Purif 2006;24:311-316.

2 Eleftheriadis T, Kartsios C, Liakopoulos V, Antoniadi G, Ditsa M, Papadopoulos C, Anifandis G, Skirta A, Markala D, Stefanidis I: Does hepcidin affect erythropoiesis in hemodialysis patients? Acta Haematol 2006; 116 (DOI: 10.1159/000095873).

3 Małyszko J, Małyszko JS, Hryszko T, Pawlak $\mathrm{K}$, Mysliwiec M: Is hepcidin a link between anemia, inflammation and liver function in hemodialyzed patients? Am J Nephrol 2005; 25:586-590

4 Ganz T: Hepcidin, a key regulator of iron metabolism and mediator of anemia of inflammation. Blood 2003;102:783-788.

5 Dallalio G, Law E, Means RT Jr: Hepcidin inhibits in vitro erythroid colony formation at reduced erythropoietin concentrations. Blood 2006;107:2702-2704.

\section{KARGER}

Fax +41613061234 E-Mail karger@karger.ch www.karger.com
(C) 2006 S. Karger AG, Base

$0253-5068 / 06 / 0246-0538 \$ 23.50 / 0$

Accessible online at:

www.karger.com/bpu
Theodoros Eleftheriadis, MD

Department of Nephrology, University Hospital of Larissa

Mezourlo Hill

GR-41110 Larissa (Greece)

Tel. +30 2410681 668, Fax +30 2410670 242, E-Mail elefthe@otenet.gr 


\title{
Reply \\ to the Letter of Eleftheriadis et al.
}

\author{
Shih-Ping Hsu ${ }^{a, b, c}$ Chih-Kang Chiang ${ }^{a, b}$ Chiang-Ting Chienc Kuan-Yu Hung ${ }^{a, b}$ \\ ${ }^{\mathrm{a}}$ Department of Internal Medicine, Far Eastern Memorial Hospital, and Departments of ${ }^{\mathrm{b}}$ Internal Medicine and \\ ${ }^{c}$ Clinical Research, National Taiwan University Hospital, Taipei, Taiwan
}

Sir,

We are pleased to know that not only our group [1], but also other teams are interested in studying the relationships between plasma hepcidin (prohepcidin) levels and anemia in hemodialysis (HD) patients $[2,3]$. However, there are apparently some discrepancies in the findings and interpretations among the studies.

Eleftheriadis et al. [2] stated they found that serum prohepcidin levels were negatively correlated with hematocrit (Hct) in their HD patients, compatible with the findings reported by Małyszko et al. [3]. Furthermore, they concluded that prohepcidin was the major and negative determinant of Hct. On the other hand, our group has found a positive correlation between plasma prohepcidin levels and Hct, suggesting prohepcidin expression might be positively regulated by Hct [1]. Kulaksiz et al. [4] have also found that dialysis patients without renal anemia have higher levels of plasma prohepcidin than those in the patients with renal anemia.

Indeed, many studies have proposed that hepcidin inhibits intestinal iron absorption and iron release from macrophages, and causes anemia of chronic disease (ACD) with low transferrin saturations and high ferritin levels. However, it would not be the case in renal anemia. Compatible with the findings reported by
Eleftheriadis et al. [2], we failed to find any significant correlation between plasma prohepcidin levels and iron profiles in HD patients. The possible explanations have been stated in our article [1]. Moreover, Nicolas et al. [5] reported in their experimental study that anemia suppresses the expression of hepcidin, indicating that low Hct would suppress the expression of prohepcidin in a feedback manner. Therefore, it is reasonable that there is a positive correlation between Hct and prohepcidin levels in HD patients.

We agree the major limitation in studying the role of hepcidin in renal anemia in HD patients is the lack of a feasible, clinical method to detect plasma levels of hepcidin rather than prohepcidin. Before further conclusive results can be proposed concerning the relationship between plasma hepcidin (prohepcidin) levels and anemia in HD patients, it is mandatory to first clarify the relationship between plasma hepcidin and prohepcidin levels in HD patients.

\section{References}

1 Hsu SP, Chiang CK, Chien CT, Hung KY: Plasma prohepcidin positively correlates with hematocrit in chronic hemodialysis patients. Blood Purif 2006;24:311-316.
2 Eleftheriadis T, Liakopoulos V, Kartsios C, Antoniadi A, Atmatzidis E, Anifandis G, Oikonomidou E, Markala D, Stefanidis I: Does hepcidin affect erythropoiesis in hemodialysis patients? XLIII ERA-EDTA Congress, Glasgow, 2006, SP431.

3 Małyszko J, Małyszko JS, Hryszko T, Pawlak $\mathrm{K}$, Mysliwiec M: Is hepcidin a link between anemia, inflammation and liver function in hemodialyzed patients? Am J Nephrol 2005; 25:586-590.

4 Kulaksiz H, Gehrke SG, Janetzko A, Rost D, Bruckner T, Kallinowski B, Stremmel W: Pro-hepcidin: expression and cell specific localisation in the liver and its regulation in hereditary haemochromatosis, chronic renal insufficiency, and renal anemia. Gut 2004; 53:735-743.

5 Nicolas G, Chauvet C, Viatte L, Danan JL, Bigard X, Devaux I, Beaumont C, Kahn A, Vaulont $\mathrm{S}$ : The gene encoding the iron regulatory peptide hepcidin is regulated by anemia, hypoxia, and inflammation. J Clin Invest 2002;110:1037-1044.

Shih-Ping Hsu, MD

Department of Internal Medicine

Far Eastern Memorial Hospital, No. 21, Sec. 2

Nan-Ya South Road, Pan-Chiao

Taipei (Taiwan)

Tel. +886289667000 , ext. 1164

Fax +886289665567

E-Mail shihping99@sina.com.tw 